\title{
PEMBERDAYAAN NELAYAN SUKU BAJO DALAM MENINGKATKAN PENDAPATAN KELUARGA DI DESA MANTIGOLA KECAMATAN KALEDUPA KABUPATEN WAKATOBI
}

\author{
Yulia Chandra', Darmin Tuwu', Ratna Supiyah ${ }^{3}$ \\ ${ }^{1}$ Jurusan Ilmu Kesejahteraan Sosial FISIP Universitas Halu Oleo, yuliachandra1995@gmail.com \\ ${ }^{2}$ Jurusan Ilmu Kesejahteraan Sosial FISIP Universitas Halu Oleo, darmintuwu@gmail.com \\ ${ }^{3}$ Jurusan Sosiologi FISIP Universitas Halu Oleo, rtnsupiyah@gmail.com
}

\begin{abstract}
The purpose of this study was to find out the process and the impact of empowering Bajo Tribe fishermen in increasing family income in Mantigola Village, Kaledupa District, Wakatobi Regency. This study uses qualitative research methods, with emphasis on descriptive and analysis. This research was conducted in Mantigola Village, Kaledupa District, Wakatobi Regency. The informants in this study were 14 people namely, village secretary, and fishing community in Mantigola Village. Data collection techniques consist of library research, and field research using observation, interview and documentation techniques. The data analysis technique is descriptive qualitative. The results of the study showed that, after empowering fishermen, it was enough to have a positive impact on the welfare of the community in Mantigola Village, Kaledupa District, Wakatobi Regency. The impact of empowering fishermen can be seen in the social, economic and political aspects, which show results that are increasing and different from before. In addition, with the empowerment of fishermen's income increasing from before the existence of empowerment activities. Empowerment of fishermen also increases the facilities and infrastructure of fishing fishermen to support fishing activities carried out by fishermen every day. In the empowerment activities the fishermen of the village government always provide skills socialization in the form of training to fishermen so that the community knows the targets that must be achieved for family welfare. The conclusion of this study shows that the impact of empowerment on increasing income and welfare of fishermen in Mantigola Village, Kaledupa Subdistrict, Wakatobi District, has had a positive impact on the welfare of the community which is increasing after empowerment.
\end{abstract}

\begin{abstract}
ABSTRAK
Tujuan penelitian ini adalah untuk mengetahui proses dan dampak pemberdayaan nelayan Suku Bajo dalam meningkatkan pendapatan keluarga di Desa Mantigola Kecamatan Kaledupa Kabupaten Wakatobi. Penelitian ini menggunakan metode penelitian kualitatif, dengan penekanan pada deskriptif dan analisis. Penelitian ini dilaksanakan di Desa Mantigola Kecamatan Kaledupa Kabupaten Wakatobi. Informan dalam penelitian ini berjumlah 14 orang yaitu, sekretaris desa, serta masyarakat nelayan di Desa Mantigola. Teknik pengumpulan data terdiri dari penelitian kepustakaan, dan penelitian lapangan menggunakan teknik observasi, wawancara dan dokumentasi. Teknik analisis data bersifat deskriptif kualitatif. Hasil penelitian menunjukkan bahwa, setelah pemberdayaan nelayan cukup memberikan dampak positif terhadap kesejahteraan masyarakat di Desa Mantigola Kecamatan Kaledupa Kabupaten Wakatobi. Dampak dari pemberdayaan nelayan ini dapat dilihat pada aspek sosial, ekonomi dan politik, dimana menunjukkan hasil yang meningkat dan berbeda dari sebelumnya. Selain itu dengan adanya pemberdayaan pendapatan nelayan meningkat dari sebelum adanya kegiatan pemberdayaan. Pemberdayaan nelayan juga meningkatkan sarana dan prasarana melaut nelayan guna menunjang aktivitas menangkap ikan yang dilakukan oleh nelayan setiap harinya. Dalam kegiatan pemberdayaan nelayan pemerintah desa selalu memberikan sosialisasi keterampilan berupa pelatihan kepada nelayan sehingga masyarakat mengetahui target yang harus dicapai demi kesejahteraan keluarga. Kesimpulan penelitian ini menunjukkan bahwa dampak pemberdayaan terhadap peningkatan pendapatan dan kesejahteraan nelayan di Desa Mantigola Kecamatan Kaledupa Kabupaten Wakatobi cukup memberikan dampak positif terhadap kesejahteraan masyarakat yang semakin meningkat setelah adanya pemberdayaan.
\end{abstract}

Key Words: Empowerment, Bajo Fishermen, Income. 


\section{PENDAHULUAN}

Desa Mantigola merupakan bagian wilayah administrasi dari Kecamatan Kaledupa yang berada di wilayah laut. Pemukiman masyarakat berada di atas timbunan batu-batu karang yang sengaja dibuat oleh masyarakat untuk fondasi rumah dan sebagian lagi membuat rumah gantung dengan fondasi kayu yang sebagian langsung menancap ke laut sedangkan untuk sarana penghubung sebagai jalan lingkungan menggunakan jalan titian.

Wilayah Desa Mantigola jika dilihat dari jauh ibarat sebuah pulau kecil dan untuk menjangkau Desa Mantigola dari daratan Pulau Kaledupa dapat menggunakan perahu atau katinting dengan waktu tempuh kurang lebih 2-3 menit dan jalan titian $250 \mathrm{~m}$ dan jalan batu $400 \mathrm{~m}$. Jarak Desa Mantigola dengan kecamatan 3,5 km dengan luas wilayah 14,28 Ha dan luas wilayah pemukimannya $3 \mathrm{Ha}$ (sumber data Monografi desa).

Berdasarkan data yang diperoleh dari Kantor Desa Mantigola, jumlah penduduk di Desa Mantigola yaitu terdiri dari 344 Kepala Keluarga, dimana jumlah keseluruhan masyarakatnya ialah 861 jiwa dengan perbandingan 420 jiwa penduduk laki-laki dan 441 jiwa penduduk perempuan yang tersebar dalam 2 dusun dan jumlah ini merupakan penduduk asli Desa Mantigola yakni penduduk lokal. Keadaan kependudukan (demografis) merupakan salah satu aspek yang ditelaah dalam tulisan ini. Keadaan demografis mencakup kondisi keadaan penduduk, mata pencaharian dan pendidikan.

Laju pertumbuhan penduduk Desa Mantigola sendiri cenderung rendah. Berdasarkan data BPS Kecamatan Kaledupa tahun 2019 menunjukan bahwa pada tahun 2018 jumlah penduduk di Desa Mantigola sebesar 841 jiwa. Mata pencaharian utama suku Bajo di Desa Mantigola adalah mencari ikan dengan cara yang masih terbilang tradisional, seperti memancing, memanah, dan menjaring ikan. Pendidikan masyarakat di Desa Mantigola didominasi oleh masyarakat yang tidak tamat SD dan tamat SD dimana jumlah suku Bajo di Desa Mantigola yang tidak tamat SD sebanyak 255 orang dan yang tamat SD sebanyak 348 orang, sedangkan untuk masyarakat Suku Bajo di Desa Mantigola tamatan SMP sebanyak 116 orang, tamatan SLTA/SMA senbanyak 78 orang, yang menempuh pendidikan di tingkat perguruan tinggi level Diploma sebanyak 17 orang dan S1 sebanyak 47 orang.

Menurut cerita, Desa Mantigola dahulu sering dijadikan sebagai tempat persinggahan masyarakat rute dari kampung ke kampung dan sering menjual gula, dtinjau dari kata manti (bahasa bajo) berarti tempat berlabuhnya penjual gula.Asal mula Suku Bajo Desa Mantigola merupakan orang-orang yang berkelana menyusuri pantai Wakatobi termasuk Kaledupa mereka datang secara berkelompok menggunakan perahu. Untuk memenuhi berbagai kebutuhannya, Suku Bajo Desa Mantigola menjalin kerjasama dengan orang darat, terutama setelah tinggal menetap di dekat wilayah daratan pulau Kaledupa.

Di Desa Mantigola Kecamatan Kaledupa, hampir rata-rata penduduknya bekerja sebagai nelayan, karena tidak ada pekerjaan yang bisa mereka lakukan kecuali menangkap ikan yang ada di laut. Menurut Nur Isiyana Wianti (2011), di Desa Mantigola sendiri jumlah nelayan aktif sebanyak 140 dari 861 orang jumlah penduduk keseluruhan desa tersebut dan terdapat 13 buah pukat, 8 jaring dan 30 alat tangkap pancing. Sementara jumlah perahu kapal penangkap hanya terdapat 1 buah 
kapal motor, dan 30 buah perahu tanpa motor. Pemerintah Desa Mantigola sudah memberikan bantuan berupa perahu, jaring ikan, tombak, dan kacamata renang kepada masyarakat desa agar dapat dimanfaatkan untuk membantu meningkatkan hasil tangkapan para nelayan. Kemudian, dari segi pemukiman, Bajo Mantigola tetap mempertahankan ciri khas pemukiman tradisional Suku Bajo dengan ciri khas bertempat tinggal di suatu rumah yang terbuat dari kayu dan bambu. Mulai dari jalan raya terlihat jembatan-jembatan bamboo dan/atau kayu yang menyebar keseluruh rumahrumah. Jembatan tersebut dipergunakan ketika air laut sedang surut, sebab ketika air laut sedang pasang, nelayan Suku Bajo Mantigola lebih senang menumpangi perahu dayung yang khusus dipergunakan untuk mengambil air minum di daratan.

Hampir seluruh masyarakat Bajo bermata pencaharian sebagai nelayan atau bekerja di laut. Dengan kata lain, kehidupan orang Bajo selalu dikaitkan dengan laut. Suku Bajo yang bekerja di laut tidak hanya didominasi oleh kaum laki-laki saja tetapi kaum perempuan Bajo juga banyak yang bekerja di laut sebagai nelyan. Secara keseluruhan pendapatan suku Bajo yang bermata pencaharian sebagai nelayan rendah, namun mereka masih dapat memenuhi kebutuhan rumah tangga dan bertahan hidup dengan penghasilan yang pas-pasan tersebut (Tuwu, dkk, 2019). Rendahnya tingkat pendapatan dan kesejahteraan nelayan Bajo antara lain disebabkan oleh karena rendahnya produktivitas dan pendapatan akibat adanya fluktuasi musim ikan.

Musim merupakan masalah besar yang dihadapi nelayan apalagi nelayan tradisional seperti halnya nelayan Suku Bajo Mantigola. Perubahan cuaca dan iklim merupakan rintangan yang harus dihadapi nelayan dan hasil tangkapan nelayan juga sangat bergantung pada keadaan bulan terang dan gelap. Ketika bulan terang, maka hasil tangkapan nelayan Bajo berkurang, di situlah tingkat kesabaran nelayan diuji. Biasanya pada keadaan seperti ini kondisi sosial ekonomi keluarga mengalami penurunan, karena mereka hanya menggantungkan hidupnya pada hasil laut saja. Tingkat pendapatan yang relatif rendah atau bahkan tidak ada sama sekali pada waktu "bulan terang" membuat mereka harus memenuhi kebutuhan hidup melalui upaya-upaya tertentu, karena para nelayan Suku Bajo di Desa Mantigola ini tidak memiliki penghasilan yang tetap dan varian pekerjaan.

Ketika bulan di langit dalam keadaan terang (bulan terang), maka nelayan Bajo tidak turun melaut, karena di saat bulan terang hasil tangkapan ikan nelayan Bajo berkurang. Sebaliknya pada waktu bulan gelap, ikan-ikan banyak sehingga hasil tangkapan ikan pun banyak. Keadaan seperti ini terus berlanjut dan dirasakan oleh nelayan Bajo Desa Mantigola dari bulan ke bulan sepanjang tahun. Dengan kondisi tersebut, nelayan Bajo harus mencari varian pekerjaan dan alternatif mata pencaharian selain sebagai nelayan, supaya dapur "tetap berasap" setiap harinya.

Khusus kaum perempuan suku Bajo, harusnya mereka mempunyai pekerjaan dan keterampilan lain di darat selain berperan sebagai nelayan, misalnya saja dengan membuka toko, warung atau kios-kios kecil di rumahnya, menjual kue, menjual sembako, belajar aneka jenis keterampilan, dan lain-lain sebagaimana telah dilakukan oleh perempuan-perempuan non Bajo. Hasil penelitian Tuwu, (2018) menunjukkan bahwa betapa besar peran perempuan dalam memenuhi ekonomi rumah tangga. Peran perempuan tidak hanya di ranah domestik (rumah tangga), tetapi juga perempuan dapat berperan di sektor publik, antara lain dengan membuka toko, kios, menjadi penjual makanan dan minuman, penjual sate pokea, gogos, dan lain-lain. 
Oleh karena itu, pemberdayaan komunitas nelayan khususnya Suku Bajo Mantigola ini merupakan langkah yang sangat krusial dalam mencapai tujuan dalam memanfaatkan kekayaan laut di sekitarnya.Untuk itu melalui pemerintah desa salah satu upaya alternatifnya adalah melakukan pemberdayaan pada masyarakat khususnya nelayan Suku Bajo di Desa Mantigola sebagai solusi yang dapat mengangkat harkat dan martabat, serta derajat nelayan Suku Bajo. Berdasarkan uraian tersebut di atas, peneliti tertarik untuk lebih jauh mengetahui tentang "Pemberdayaan Nelayan Suku Bajo dalam Meningkatkan Pendapatan Keluarga (Studi pada Masyarakat Suku Bajo di Desa Mantigola Kecamatan Kaledupa Kabupaten Wakatobi)”.

\section{METODE}

Jenis penelitian yang akan dilakukan adalah penelitian deskriptif kualitatif yang bertujuan untuk memberikan gambaran atau penjelasan tentang proses pemberdayaan nelayan Suku Bajo di Desa Mantigola Kecamatan Kaledupa Kabupaten Wakatobi. Objek penelitian ini adalah nelayan Suku Bajo yang ada di Desa Mantigola, namun peneliti hanya memilih sebanyak 14 informan. Peneliti menggunakan teknik purposive sampling yaitu memilih informan yang dianggap mengetahui permasalahan sehingga akan memudahkan peneliti menjelajahi objek atau situasi sosial tertentu dan dapat dipercaya untuk dijadikan sumber data yang Valid (Sugiyono, 2009). Untuk memperdalam hasil penelitian dilakukan pula wawancara mendalam terkait kontribusi pemerintah desa Mantigola dalam pemberdayaan nelayan Suku Bajo dalam meningkatkan pendapatan keluarga.

Metode Pengumpulan Data melalui pengamatan (observation), Wawancara mendalam (indepth interview), dan melalui dokumentasi untuk mendapatkan data primer maupun data sekunder. Data primer diperoleh melalui hasil wawancara dan observasi, sedangkan data sekunder diperoleh melalui dokumentasi, laporan resmi, publikasi berkala, dan studi literatur.

Teknik analisis data dilakukan berdasarkan pada teknik analisis deskriptif-kualitatif, mulai dari proses awal penelitian hingga proses akhir penelitian. Tujuannya adalah supaya dapat menjawab seluruh pertanyaan penelitian, menemukan temuan penelitian.

\section{HASIL DAN PEMBAHASAN}

\section{Proses Pemberdayaan Nelayan Suku Bajo di Desa Mantigola Kecamatan Kaledupa Kabupaten Wakatobi}

Adapun tahapan-tahapan kegiatan pemberdayaan nelayan yang dilakukan Dinas Perikanan dan Ilmu Kelautan Kabupaten Wakatobi di Desa Mantigola secara rinci yaitu, sebagai berikut:
a. Tahap Seleksi Lokasi/wilayah
b. Tahap Sosialisasi Pemberdayaan Nelayan
c. Tahap Proses Kegiatan
d. Tahap Pemandirian Nelayan

Berpegang pada prinsip pemberdayaan nelayan yang bertujuan untuk memandirikan masyarakat dan meningkatkan taraf hidupnya, maka arah pemandirian masyarakat adalah berupa pendampingan untuk menyiapkan masyarakat agar benar-benar mampu mengelola kegiatannya. 


\section{Pemberian Bantuan Sarana dan Prasarana Melaut Nelayan}

Sarana dan prasarana merupakan faktor penting dalam menunjang usaha melaut nelayan.Sarana dan prasarana merupakan sebuah urat nadi dari berbagai macam kegiatan dan usaha. Minimnya sarana dan prasarana yang dimiliki oleh para nelayan sangat mempengaruhi hasil tangkapan mereka. Dengan melihat kondisi tersebut pemerintah Desa Mantigola memberikan bantuan sarana prasarana melaut bagi nelayan diantaranya: "jaring ikan, tombak ikan, kacamata laut, senter dan panah ikan". Bantuan ini sudah diterima oleh nelayan dan diberikan secara bertahap, hal ini diperkuat juga oleh hasil wawancara peneliti dengan informan Bapak Hawi (34) yang mengatakan bahwa:

"Ada bantuan dari desa dan saya juga dapat, bantuan yang saya dapat jaring ikan, senter dan panah. Kalojaring ikan saya dapat tahun 2016 kalo senter dengan panah ikan 2018 kemarin tapi saya sudah lupa bulan berapa itu hari dapat mungkin bulan-bulan 9 kayanya. Saya sudah pake mesin katinting yang saya dapat dari desa, itu saya sudah pasang di bodi saya (sambil menunjuk kearah perahu/sampan yang diparkir dekat rumahnya)". (Wawancara Sabtu, 8 Juni 2019).

Hal senada juga diungkapkan oleh Bapak Dasri (34) yang mengatakan kepada peneliti dalam uraian percakapan sebagai berikut:

"Saya dapat bantuan jaring ikan dari desa tahun 2017 jaringnya itu ukuran $3 \mathrm{~cm}$. Dulu saya di kasih yang $2 \mathrm{~cm}$ tapi saya jual karena saya biasa pake jaring yang $3 \mathrm{~cm}$, kalo $3 \mathrm{~cm}$ bisa di pake untuk tangkap ikan yang besar. 2018 saya dapat bantuan panah dengan senter, nda tau 2019 ini dapat apa lagi. Tapi sekarang sudah bagus kita dikasih bantuan itu sesuai yang kita mau". (Wawancara Sabtu, 8 Juni 2019).

Dari hasil wawancara peneliti dengan informandapat diketahui bahwa bantuan dari pemerintah desa diberikan secara bertahap kepada para nelayan dan tidak setiap tahunnya akan diberikan terus melainkan tahun berikutnya akan diberikan lagi kepada nelayan lain. Hal ini dilakukan dengan maksud agar pemberian bantuan tersebut terkesan merata keseluruh nelayan agar tidak ada kecemburuan dari nelayan tersebut.

\section{Sosialisasi Program Bantuan dan Penggunaan Alat-Alat Tangkap Ikan}

Sosialisasi ini dimaksudkan untuk menjadikan nelayan Suku Bajo di Desa Mantigola sebagai masyarakat yang tangguh, dan mampu sendiri. Dalam proses sosialisasi melibatkan pemerintah, maupun masyarakat. Dalam hal ini pemerintah desa harus menciptakan iklim yang kondusif dan melakukan pembinaan dan pengembangan berupa bimbingan dan bantuan lainnya kepada nelayan. Di Desa Mantigola, dilakukan upaya memberikan sosialisasi atau penyuluhan atas potensi yang dimiliki oleh masyarakat untuk kemudian dapat dikembangkan. Selain itu, nelayan juga diberi penjelasan tentang bagaimana cara mereka mengelola keuangan dalam hal ini membelanjakan uang hanya untuk keperluan utama atau kebutuhan primer.

\section{Dampak Pemberdayaan yang dilakukan Oleh Pemerintah Desa Terhadap Nelayan Suku Bajo di Desa Mantigola Kecamatan Kaledupa Kabupaten Wakatobi dalam Meningkatkan Pendapatan Keluarga}


Pemberdayaan nelayan Suku Bajo di Desa Mantigola yang dimaksudkan dalam kajian ini adalah aspek upaya yang dilakukan baik oleh nelayan itu sendiri, dan oleh pihak dari luar sehingga nelayan lebih berdaya, pendapatan meningkat dan kesejahteraan masyarakat tersebut menjadi lebih baik.

Dalam aspek sosial lebih merupakan upaya untuk meningkatkan kemampuan sumber daya manusia dan menyadarkan posisi dan peran seseorang dalam kaitannya dengan kehidupan sosial dalam komunitasnya.Dalam masyarakat Suku Bajo di Desa Mantigola, posisi sosial menetukan perlakukan seseorang dari komunitasnya baik karena perbuatan yang dilakukannya sendiri maupun perbuatan yang dilakukan komunitas.

Berdaya dalam aspek ekonomi adalah pendekatan yang diutamakan kepada nelayan kelas bawah untuk mampu beraktifitas dalam bidang ekonomi dan memiliki penghasilan yang lebih baik, sehingga mampu menanggung dampak negatif dari pertumbuhan yang terjadi.Lebih berdaya dalam aspek ekonomi mengandung arti bahwa nelayan dapat meningkatkan kemandirian dalam bidang ekonomi sehingga dari kemandirian tersebut mampu menambah penghasilan keluarga.Nelayan lebih dapat mengatur kehidupannya secara layak menurut ukuran-ukuran yang disepakati bersama dalam kelompok masyarakat nelayan.Dengan demikian tingkat layak secara ekonomi dari tiap nelayan mungkin saja berbeda, namun demikian ada ukuran yang diterima oleh masyarakat secara umum.

Pemberdayaan politik lebih mengarah kepada upaya untuk menyadarkan masyarakat untuk berpartisipasi dalam politik dan meningkatkan posisi tawar masyarakat terhadap pemerintah atau pihak-pihak lainnya, yang meliputi aspek-aspek penegakan keadilan, kepemimpinan politik, dan pelayanan public. Berikut hasil wawancara peneliti dengan beberapa informan di Desa Mantigola mengenai dampak pemberdayaan yang mereka rasakan.

Wawancara peneliti dengan Bapak Yungseng (28):

"Iya ada kegiatan itu hari di balai desa kita disuruh kumpul jam 9 pagi. Katanya ada dari wanci (Kabupaten) mau datang kesini. Kegiatannya itu bagus kitadikasih tau cara tangkap ikan dengan baik. Saya selalu ikut kegiatannya kalo tidak ke laut, kalo saya ke laut biasa isteri saya yang gantikan”. (Wawancara Jumat, 14 Juni 2019).

Demikian pula wawancara peneliti dengan Bapak Sadir (29):

"Ada sosialisasi dari desa setiap sebulan atau dua bulan sekali diadakan kegiatannya itu bagus.Biasa kegiatannya kita dikasih tau cara-cara menangkap ikan supaya banyak kita juga dikasih tau cuaca yang bagus buat cari ikan trus di kasih tau juga soal keuangan kalo banyak dapat uang jangan dibelanjakan sampai habis tapi ditabung. Dan Alhamdulillah sekarang isteri saya juga sudah bisa mengelola keuangan keluarga, kalo uang hasil jual ikan banyak dia tabung untuk nanti keperluan makan dan anak-anak sekolah. Menurut saya kegiatannya bermanfaat bagi kami bisa membantu kita dari apa yang nda ditau menjadi tau. Pertemuan terakhir bulan kemarin pas pergi melaut saya langsung kerjakan". (Wawancara Rabu, 12 Juni 2019).

Wawancara peneliti dengan Bapak Rames (32): 
"Iya ada biasa kegiatan pertemuan diadakan di balai desa saya selalu datang kalo ada undangan, atau isteri saya.Kegiatannya itu sosialisasi dari pemerintah desa atau juga orang dari Kabupaten. Bagus dan bermanfaat apalagi buat kami nelayan kecil kalo cari ikan taunya hanya begitu-begitu saja kalo bukan mancing ya menjaring.Kita diberikan semacamcara tombak ikan, saya kan awalnya nda tau nda pake tombak cuman pake jaring saja kalo cari ikan" (Wawancara Rabu, 12 Juni 2019).

Berdasarkan hasil wawancara peneliti dengan beberapa informan diatas dapat ditarik kesimpulan bahwa dampak dari pemberdayaan nelayan Suku Bajo di Desa Mantigola adalah positif dan sangat membantu menunjang aktivitas nelayan dalam mencari ikan. Dari uraian wawancara tersebut diketahui bahwa awalnya nelayan tidak mempunyai keterampilan atau pemahaman mengenai bagaimana cara menangkap ikan dengan baik dan ramah lingkungan sehingga dengan adanya kegiatan pemberdayaan nelayan menjadi tahu. Selain itu, isteri para nelayan sudah dapat mengelola keuangan dalam rumah tangga seperti merubah pola konsumtif dengan bersikap hemat dan menabung. Hal ini dapat membantu nelayan untuk meningkatkan taraf hidup yang lebih baik dari sebelumnya. Dengan hasil tangkapan ikan yang banyak akan banyak pula hasil jualnya sehinga hal ini mempengaruhi pendapatan yang diperoleh nelayan.

Pemberdayaan nelayan Suku Bajo di Desa Mantigola secara umum telah memberi perubahan yang berarti dalam kehidupan nelayan.Dengan adanya bantuan sarana prasarana dan peralatan menangkap ikan yang diberikan pemerintah Desa Mantigola membuat aktivitas nelayan menjadi lebih berkembang.Seperti awalnya nelayan hanya menggunakan dayung untuk melaut sekarang sudah bisa memakai mesin katinting untuk perahu/sampan mereka. Nelayan mulai dapat merencanakan kehidupan yang lebih baik.

\section{PENUTUP}

Berdasarkan pembahasan yang telah dikemukakan di atas, maka dapat dikemukakan kesimpulan sebagai berikut:

1. Bahwa pemerintah desa telah melakukan proses pemberdayaan terhadap nelayan Suku Bajo di Desa Mantigola berupa pemberian bantuan sarana dan prasarana melaut nelayan seperti:

a) Tahapan pelaksanaan kegiatan pemberdayaan nelayan,

b) Pemberian bantuan sarana prasarana melaut/alat-alat tangkap ikan (Mesin katinting, bodi batang/perahu, tombak ikan, jaring ikan, kacamata renang, panah ikan, senter, mesin katinting),

c) Sosialisasi keterampilan melaut dan pengelolaan keuangan keluarga nelayan, serta

d) Mendirikan koperasi nelayan.

2. Kegiatan pemberdayaan ini merupakan kegiatan yang sangat bermanfaat dan memberikan dampak baik bagi nelayan terutama dalam membantu nelayan meningkatkan hasil tangkapan dan pendapatan keluarga. Pemberdayaan telah membantu nelayan terutama dalam menyediakan sarana prasarana dan perlengkapan menangkap ikan.Secara umum dampak pemberdayaan nelayan adalah adanya peningkatan pendapatan yang dirasakan para nelayan. Hal ini juga menyebabkan kesejahteraan keluarga nelayan menjadi lebih baik dari sebelumnya kebutuhan sehari-hari dapat terpenuhi dengan baik. Dalam pemberdayaan nelayan berpartisipasi aktif 
dalam kegiatan kemasyarakatan dan mereka menjadi aktif dalam berinteraksi sosial dengan nelayan lainnya sehingga menciptakan solidaritas diantara anggota masyarakat. Dampak lain yang dirasakan yaitu nelayan berdaya dalam aspek ekonomi yang mengandung arti bahwa nelayan dapat meningkatkan kemandirian dalam bidang ekonomi sehingga dari kemandirian tersebut mampu menambah penghasilan keluarga. Nelayan memiliki kendali dan tanggung jawab penuh terhadap setiap pengambilan keputusan dan perencanaan yang berkaitan dengan pembangunan dalam komunitasnya.

Dengan adanya kegiatan sosialisasi yang diberikan pemerintah desa maupun pemerintah kabupaten nelayan mendapat pengetahuan lebih mengenai sumber daya laut sehingga dapat memanfaatkan potensi yang ada dengan baik.Nelayan di Desa Mantigola lebih berdaya dari sebelumnya hal ini dibuktikan dengan kondisi rumah sudah permanen yang awalnya hanya berupa rumah panggung terbuat dari kayu.Selain itu, tidak sedikit orang tua sudah bisa membawa pendidikan anak-anak mereka ke jenjang yang lebih tinggi seperti perguruan tinggi dan semua itu hanya dengan bekerja sebagai panangkap ikan.

\section{DAFTAR PUSTAKA}

Anggi H, Ignasia, 2016. Efektivitas Dan Dampak Program Pemberdayaan Nelayan Kerang Hijau (Studi di Pulau Pasaran Kelurahan Kota Karang Kecamatan Teluk Betung Timur Kota Bandar Lampung). Skripsi. Fakultas Ilmu Sosial dan Ilmu Politik, Universitas Lampung Bandar, Lampung.

Kaswandi, 2017. Peran Pemerintah Daerah dalam Pemberdayaan Masyarakat Nelayan di Kabupaten Takalar. Skripsi. Program Studi Ilmu Pemerintahan Fakultas Ilmu Sosial Dan Ilmu Politik, Universitas Hasanuddin Makassar.

Kusnadi, 2008. Akar Kemiskinan Nelayan. LKiS Yogyakarta.

Maemunah, Siti. 2015. Koperasi Perikanan Laut "Mina Sumitra” dalam Pemberdayaan Nelayan Kecil Desa Karangsor Kecamatan Indramayu Kabupaten Indramayu, Skripsi. IAIN Syekh Nurjati, Cirebon.

Manik, Tumpak, dkk. 2012. Sikap Nelayan Terhadap Program Pengembangan Perikanan Tangkap Khususnya Pemberian Bantuan Alat Tangkap Ikan (Studi Kasus: Kecamatan Teluk Mengkudu Kabupaten Serdang Bedagai). Jurnal. Program Studi Agribisnis, Departemen Agribinis Fakultas Pertanian, Universitas Sumatera Utara.

Nur, Isiyana Wianti. 2011. Kapitalisme Lokal Suku Bajo: Studi Kasus Nelayan Bajo Moladan Mantigola, Kabupaten Wakatobi Provinsi Sulawesi Tenggara. Tesis. Sekolah Pasca Sarjana Institut Pertanian Bogor.

Rahman, Andi. 2018. Suku Bajo Dan Kemiskinan (Studi Kasus Kemiskinan Nelayan Suku Bajo di Desa Saur Saibus Kecamatan Sapeken Kabupaten Sumenep, Tesis. Universitas Islam Negeri Sunan Ampel, Surabaya. 
Rahmanto, Derta, dkk. 2015. Pemberdayaan Masyarakat Pesisir Pulau Untung jawa dalam Upaya Meningkatkan Kesadaran Hukum dan Kemandirian Nelayan. Jurnal. Fakultas Hukum Universitas YARSI, Jakarta.

Rukminto, Isbandi A, 2013. Kesejahteraan Sosial (Pekerjaan Sosial, Pembangunan Sosial, dan Kajian Pembangunan). PT. Raja GrafindoPersada, Jakarta.

Sugiri, Lasiman. 2012. Peranan Pemerintah Daerah dalam Pemberdayaan Masyarakat. Jurnal, STISIPOL Dharma Wacana Metro, Indonesia.

Tuwu, Darmin, et al. 2019. Empowering Bajo Women in Managing Household Finances In Bajo Indah Village, Soropia District, Konawe Regency, Southeast Sulawesi. WoMELA-GG, EAI Publishing.

Tuwu, Darmin. 2018. Peran Pekerja Perempuan Dalam Memenuhi Ekonomi Keluarga:Dari Peran Domestik Menuju Sektor Publik. Jurnal Penelitian dalam Al-Izzah volume 13 Nomor 1 (Mei 2018). Ilmu Kesejahteraan Sosial, Universitas Halu Oleo, Kendari. 